Original Article

\title{
Functional exercise capacity, physical activity, and respiratory and peripheral muscle strength in pulmonary hypertension according to disease severity
}

\author{
Melda Saglam, PT, PhD ${ }^{1)^{*}}$, Naciye Vardar-Yagli, PT, PhD ${ }^{1)}$, \\ Ebru Calik-Kutukcu, PT, PhD ${ }^{1)}$, Hulya Arikan, PT, PhD ${ }^{1)}$, Sema Savci, PT, PhD ${ }^{2)}$, \\ Deniz Inal-Ince, PT, $\mathrm{PhD}^{1)}$, Ali Akdogan, MD ${ }^{3)}$, Lale Tokgozoglu, MD ${ }^{4)}$ \\ 1) Department of Physiotherapy and Rehabilitation, Faculty of Health Sciences, Hacettepe University: \\ 06100 Samanpazari, Ankara, Turkey \\ 2) School of Physiotherapy and Rehabilitation, Dokuz Eylul University, Turkey \\ 3) Department of Internal Medicine, Faculty of Medicine, Hacettepe University, Turkey \\ 4) Department of Cardiology, Faculty of Medicine, Hacettepe University, Turkey
}

\begin{abstract}
Purpose] This study investigated functional capacity, physical activity, and respiratory and peripheral muscle strength in different functional classes of pulmonary arterial hypertension (PAH) compared with healthy subjects. [Subjects and Methods] This study included 31 patients with class II $(\mathrm{n}=16)$ or class III $(\mathrm{n}=15)$ PAH, classified according to the World Health Organization. Fifteen healthy subjects served as controls. Functional capacity was assessed using the 6-minute walk test (6MWT). Physical activity was determined using the International Physical Activity Questionnaire Short Form (IPAQ-SF). Respiratory muscle strength was measured using a mouth pressure device. Peripheral muscle strength was evaluated using a dynamometer. [Results] The 3 groups had similar demographic variables $(\mathrm{p}>0.05)$. There were significant differences in 6MWT distance, maximal inspiratory pressure, and IPAQ categorical classification between the 3 groups $(\mathrm{p}<0.05)$. Maximal expiratory pressure; total IPAQ score; and knee extensor, shoulder abductor, and hand grip strength were significantly lower in PAH patients (classes II and III) than in healthy subjects $(\mathrm{p}<0.05)$. [Conclusion] As PAH progresses, respiratory muscle strength, functional exercise capacity, and physical activity decrease. Functional class should be taken into consideration when planning rehabilitation programs for this patient group.

Key words: Pulmonary hypertension, Functional capacity, Physical activity
\end{abstract}

(This article was submitted Nov. 11, 2014, and was accepted Jan. 11, 2015)

\section{INTRODUCTION}

Pulmonary arterial hypertension (PAH) is defined by a resting mean pulmonary arterial pressure over $25 \mathrm{mmHg}$, confirmed by right heart catheterization ${ }^{1,2)}$. PAH is a rare and progressive disorder of the pulmonary circulation that leads to deterioration in cardiopulmonary function, and, ultimately, to right ventricular failure and death ${ }^{3)}$. Patients with PAH experience progressive dyspnea, fatigue, syncope, and chest pain. These symptoms lead to impaired exercise capacity, physical function, and quality of life $e^{4,5)}$.

PAH severity is classified according to a system originally developed for heart failure by the New York Heart Association (NYHA) $)^{6}$, which was later modified for PAH by the

*Corresponding author. Melda Saglam (E-mail: msaglam@ hacettepe.edu.tr)

C 2015 The Society of Physical Therapy Science. Published by IPEC Inc. This is an open-access article distributed under the terms of the Creative Commons Attribution Non-Commercial No Derivatives (by-ncnd) License $<$ http://creativecommons.org/licenses/by-nc-nd/3.0/> .
World Health Organization $(\mathrm{WHO})^{1,7)}$. This system grades clinical severity according to functional status. Grades range from class $I$, in which the disease does not affect the patient's day-to-day activities, to class IV, in which the patient is severely functionally impaired, even at rest ${ }^{4,8)}$. The WHO functional classification system links symptoms with activity limitations, and is important for assessing disease progression or monitoring the disease, as well as highlighting the need for specific treatment regimens irrespective of the underlying etiology of $\mathrm{PAH}^{4,9}, 10$ ).

There have been no studies regarding the relationships between functional class (FC) and impairments in functional capacity, physical activity, and respiratory and peripheral muscle strength. Therefore, this study was designed to compare these variables between healthy controls and patients with PAH of different FCs according to disease severity.

\section{SUBJECTS AND METHODS}

This study was performed prospectively at a single center. Thirty-one patients with PAH were included in the study; 16 had class II PAH (PAH-II) and 15 had class III 
PAH (PAH-III), based on the WHO classification system. All patients were clinically stable with no infection and no change in disease-targeted medications in the 3 months prior to the study. All patients had a negative acute reactivity test and were treated with endothelin receptor antagonists and phosphodiesterase type-5 inhibitors. Patients with severe obstructive and restrictive lung disease, severe ischemic heart disease, left heart failure, cor pulmonale, cognitive disorders, or orthopedic problems were excluded. The control group comprised 15 healthy age-, sex-, and body mass index-matched subjects.

The study protocol was approved by the Ethics Committee of Hacettepe University, and was performed in accordance with the Declaration of Helsinki. Informed written consent was obtained from all participants.

The 6-minute walk test (6MWT) was performed to assess functional capacity in all PAH patients and healthy subjects following American Thoracic Society guidelines ${ }^{11}$. Participants walked along an enclosed $30-\mathrm{m}$ corridor, and were instructed to walk at their own pace to cover as much distance as possible in 6 minutes. Subjects were allowed to stop and rest if needed. All PAH patients and healthy controls performed the test twice to account for any learning effects. Dyspnea and fatigue perception were evaluated using the modified Borg scale. Heart rate (Polar heart rate monitor, PF3000; Polar Electro, Kempele, Finland) and oxygen saturation (KTPS-01; KTMed, Seoul, Korea) also were recorded $^{12)}$.

The physical activity level was determined using the International Physical Activity Questionnaire Short Form (IPAQ-SF) - a 7-item questionnaire in which respondents estimate the frequency and duration of various activities engaged in during the previous 7 days. Scores for moderate activities, vigorous activities, and walking were calculated as durations multiplied by known metabolic equivalents (MET) per activity. MET-min scores were converted to kilocalories using the following equation: MET-min $\times$ (weight [kg] / $60 \mathrm{~kg}$ ). The sitting question is a separate score, and was not included in the physical activity score. We also used the IPAQ categorical score, which defines 3 levels of physical activity: inactive, minimally active, and sufficiently active $^{13,14)}$. The IPAQ is a valid and reliable questionnaire used for various conditions, such as chronic obstructive pulmonary disease and left heart failure.

Respiratory muscle strength was determined by measuring maximal inspiratory pressure (MIP) and maximal expiratory pressure (MEP) generated at the mouth using a mouth pressure device (MicroRPM; Micromedical, Kent, United Kingdom) ${ }^{15)}$. MIP was measured as residual volume after a maximal expiration, while MEP was measured as total lung capacity after a maximal inspiration. Tests were repeated until no further improvements were observed and there was no more than $5 \%$ difference between the 2 best values. The best value was recorded ${ }^{16)}$. Normal values for respiratory muscle strength were calculated using regression equations according to age and sex ${ }^{17}$.

Isometric muscle strength was measured bilaterally with subjects in a standard position using a handheld dynamometer (Medical Commander Powertrack II; JTECH, Salt Lake City, UT, USA). Measurements were taken for 3 peripheral
Table 1. Characteristics of the study participants

\begin{tabular}{lccc}
\hline & $\begin{array}{c}\text { PAH-II } \\
(\mathrm{n}=16)\end{array}$ & $\begin{array}{c}\text { PAH-III } \\
(\mathrm{n}=15)\end{array}$ & $\begin{array}{c}\text { Healthy } \\
\text { controls } \\
(\mathrm{n}=15)\end{array}$ \\
\hline Age, y & $48.5 \pm 12.8$ & $51.8 \pm 12.4$ & $46.7 \pm 11.2$ \\
Gender, F/M, $\mathrm{n}$ & $14 / 2$ & $11 / 4$ & $8 / 7$ \\
Height, cm & $160.1 \pm 6.2$ & $160.2 \pm 8.5$ & $163.7 \pm 8.2$ \\
Weight, kg & $65.8 \pm 11.9$ & $71.8 \pm 20.9$ & $75 \pm 13.8$ \\
BMI, kg/m ${ }^{2}$ & $25.6 \pm 3.8$ & $27.9 \pm 7.8$ & $28.1 \pm 5.6$ \\
PH etiology, n (\%) & & & \\
$\quad$ Idiopathic PH & $5(31)$ & $4(27)$ & NA \\
Associated PH & $11(69)$ & $11(73)$ & NA \\
mPAP, mmHg & $61.3 \pm 35.3$ & $73.8 \pm 27.1$ & NA \\
Disease duration, y & $5.4 \pm 4.5$ & $6.1 \pm 6.1$ & NA \\
\hline
\end{tabular}

Values are mean $\pm \mathrm{SD}$ unless otherwise noted.

BMI: body mass index; F: female; M: male; mPAP: mean pulmonary arterial pressure; PAH: pulmonary arterial hypertension; PH: pulmonary hypertension; NA: not applicable

muscle groups: shoulder abductors, hand grip, and knee extensors. Each muscle group was tested 3 times, and the highest value was recorded ${ }^{18)}$.

Data were analyzed using SPSS version 18.0 (SPSS Inc., Chicago, IL, USA), and tested for normality using the Shapiro-Wilk test. Quantitative variables were expressed as mean $\pm \mathrm{SD}$, while frequency was expressed as a percentage. One-way analysis of variance was used to compare mean values between PAH-II patients, PAH-III patients, and healthy controls. Post hoc analyses for the 3 groups were performed using Tukey's technique. The $\chi^{2}$ test was used to compare qualitative variables. $\mathrm{P}$ values of $<0.05$ were considered statistically significant.

\section{RESULTS}

Participants' characteristics are shown in Table 1. Sixteen patients were classified as having WHO FC II PAH (PAH-II group) and 15 were classified as having WHO FC III PAH (PAH-III group). PAH patients and healthy controls were well matched for age, sex, height, weight, and body mass index. Moreover, etiology and disease duration were similar between the PAH-II and PAH-III groups ( $\mathrm{p}>0.05)$.

Clinical features of PAH patients and healthy controls are shown in Table 2. 6MWT distance was significantly lower in PAH patients than in healthy controls $(\mathrm{p}<0.05)$. The distance also significantly decreased in proportion to $\mathrm{PAH}$ severity $(\mathrm{p}<0.05)$. 6MWT distance values of 14 PAH-II patients $(87.5 \%)$ and 15 PAH-III patients $(100 \%)$ were lower than the $95 \%$ confidence interval (CI) of healthy subjects (570.1-638 m).

Differences in oxygen desaturation, dyspnea, and fatigue perception in the $6 \mathrm{MWT}$ were significantly higher in PAH patients than in healthy controls $(\mathrm{p}<0.05)$.

MIP, MEP, and percentages of each were significantly lower in PAH patients than in healthy subjects $(\mathrm{p}<0.05)$. MIP also significantly decreased between PAH-II and PAHIII groups $(\mathrm{p}<0.05)$. MIP values of 11 PAH-II patients 
Table 2. Comparison of clinical features of PAH patients and healthy controls

\begin{tabular}{|c|c|c|c|}
\hline & $\begin{array}{l}\text { PAH-II } \\
(\mathrm{n}=16)\end{array}$ & $\begin{array}{l}\text { PAH-III } \\
(\mathrm{n}=15)\end{array}$ & $\begin{array}{l}\text { Healthy controls } \\
\qquad(\mathrm{n}=15)\end{array}$ \\
\hline \multicolumn{4}{|l|}{ Functional capacity } \\
\hline 6MWT distance, $\mathrm{m}$ & $438.5 \pm 113.3^{*}$ & $338.4 \pm 113.5^{\beta \S}$ & $604 \pm 61.3$ \\
\hline$\Delta \mathrm{SaO}_{2}, \%$ & $-8.2 \pm 10.1^{*}$ & $-12.6 \pm 13.2^{\beta}$ & $-0.4 \pm 0.7$ \\
\hline Maximum heart rate, $\%$ & $71.2 \pm 13.4$ & $67.4 \pm 8.7$ & $68.7 \pm 7.2$ \\
\hline$\Delta$ Dyspnea, Borg & $3.9 \pm 2.7^{*}$ & $4.6 \pm 3.2^{\beta}$ & $0.1 \pm 0.3$ \\
\hline$\Delta$ Fatigue, Borg & $3.7 \pm 2.2^{*}$ & $4.3 \pm 2.8^{\beta}$ & $0.2 \pm 0.4$ \\
\hline \multicolumn{4}{|l|}{ Muscle strength } \\
\hline MIP, $\mathrm{cmH}_{2} \mathrm{O}$ & $78.9 \pm 21.2^{*}$ & $63.5 \pm 17.1^{\beta \S}$ & $108.7 \pm 21.9$ \\
\hline MIP, \% & $83.4 \pm 27.9^{*}$ & $72.2 \pm 14.3^{\beta}$ & $115.1 \pm 24.2$ \\
\hline MEP, $\mathrm{cmH}_{2} \mathrm{O}$ & $108.8 \pm 28.9^{*}$ & $89.4 \pm 26.6^{\beta}$ & $149.1 \pm 40.1$ \\
\hline MEP, \% & $69.7 \pm 12.9^{*}$ & $59.4 \pm 12.8^{\beta}$ & $84 \pm 15.1$ \\
\hline Shoulder abductors, $\mathrm{N}$ & $101.7 \pm 18.6^{*}$ & $92.5 \pm 29.9^{\beta}$ & $156.6 \pm 38.7$ \\
\hline Hand grip, $\mathrm{N}$ & $137.3 \pm 38.7^{*}$ & $125.2 \pm 29.9^{\beta}$ & $170 \pm 41.2$ \\
\hline Knee extensors, $\mathrm{N}$ & $225.1 \pm 84.9^{*}$ & $197.6 \pm 55.6^{\beta}$ & $279.9 \pm 52.5$ \\
\hline \multicolumn{4}{|l|}{ Physical activity } \\
\hline IPAQ total PA, kcal/d & $193.5 \pm 146.8^{*}$ & $169.3 \pm 155.9^{\beta}$ & $502.6 \pm 542.6$ \\
\hline IPAQ vigorous $\mathrm{PA}, \mathrm{kcal} / \mathrm{d}$ & $0 \pm 0$ & $0 \pm 0$ & $146.4 \pm 397.8$ \\
\hline IPAQ moderate PA, $\mathrm{kcal} / \mathrm{d}$ & $91.4 \pm 114.8$ & $76.4 \pm 144.7$ & $161.3 \pm 162.9$ \\
\hline IPAQ walking, kcal/d & $102.9 \pm 80.7$ & $92.9 \pm 66.2^{\beta}$ & $194.9 \pm 160.9$ \\
\hline IPAQ sitting, $\mathrm{min} / \mathrm{d}$ & $608.6 \pm 107.5^{*}$ & $560 \pm 118.2^{\beta}$ & $440 \pm 139.2$ \\
\hline
\end{tabular}

(68.8\%) and 15 PAH-III patients $(100 \%)$ were lower than the $95 \% \mathrm{CI}$ of healthy subjects $\left(96.5-120.8 \mathrm{cmH}_{2} \mathrm{O}\right)$. MEP values of $12 \mathrm{PAH}-\mathrm{II}$ patients $(75 \%)$ and $14 \mathrm{PAH}-\mathrm{III}$ patients (93.3\%) were lower than the $95 \%$ CI of healthy subjects (126.8-171.3 $\left.\mathrm{cmH}_{2} \mathrm{O}\right)$.

Peripheral muscle strength of the shoulder abductors, hand grip, and knee extensors was significantly lower in PAH patients than in healthy subjects $(\mathrm{p}<0.05)$. Unsurprisingly, the greatest peripheral muscle weakness was observed in the PAH-III group; however, there was no significant difference between the PAH-II and PAH-III groups ( $p>0.05)$. Shoulder abductor strength in 15 PAH-II patients $(93.8 \%)$ and 14 PAH-III patients (93.3\%) was lower than the 95\% CI of healthy subjects (135.1-178 N). Knee extensor muscle strength in $10 \mathrm{PAH}-\mathrm{II}$ patients $(62.5 \%)$ and $13 \mathrm{PAH}-\mathrm{III}$ patients $(85.7 \%)$ was lower than the $95 \%$ CI of healthy subjects $(250.8-309 \mathrm{~N})$. Hand grip strength in $9 \mathrm{PAH}-\mathrm{II}$ patients $(56.3 \%)$ and 12 PAH-III patients $(80 \%)$ was lower than the $95 \%$ CI of healthy subjects $(147.2-192.8 \mathrm{~N})$.

Total energy expenditure, estimated by using the IPAQSF, was significantly lower, and total sitting time was significantly higher in PAH patients than in healthy controls $(p<0.05)$. Energy expenditure in walking was significantly different between PAH-III patients and healthy controls ( $p$ $<0.05)$.

According to IPAQ categorical classification, 10 PAH-III patients $(66.7 \%)$ were inactive and $5(33.3 \%)$ were mini- mally active. Among PAH-II patients, 4 (25\%) were inactive and $12(75 \%)$ were minimally active. In the healthy control group, 4 subjects $(26.7 \%)$ were inactive, 7 (46.7\%) were minimally active, and $4(26.7 \%)$ were sufficiently active (p $<0.05)$.

\section{DISCUSSION}

The present study investigated functional capacity, muscle strength, and physical activity in PAH patients in relation to disease severity according to WHO FC. The major finding was that functional exercise capacity, physical activity level, and respiratory and peripheral muscle strength were significantly reduced in PAH patients compared with healthy matched controls.

Functional exercise capacity, evaluated by using the 6MWT, was significantly decreased with increasing PAH severity. A previous study of PAH patients also demonstrated a decline in submaximal exercise capacity according to NYHA classification system ${ }^{8)}$. The WHO FC system is able to distinguish between classes I and IV; however, it is difficult to differentiate classes II and III.

Symptoms after the exercise test were worse in PAH patients than in healthy subjects. Patients' functional status was more related to submaximal exercise capacity than to hemodynamics. However, the WHO classification system does not identify the differences between classes II and III. 
Previous studies have demonstrated respiratory muscle weakness, especially loss of inspiratory muscle strength, in patients with $\mathrm{PAH}^{19,20)}$. The present study provides evidence that inspiratory and expiratory muscle strength are reduced in patients with $\mathrm{PAH}$ compared with healthy controls. Inspiratory muscle strength also declined from WHO FC II to WHO FC III. In contrast, Meyer et al. showed that respiratory muscle strength was independent of WHO $\mathrm{FC}^{19)}$. Our findings indicate that WHO FC can effectively identify changes in MIP.

To our knowledge, this is the first study to examine proximal upper extremity muscle strength in PAH patients in addition to the knee extensors and hand grip force ${ }^{21,22)}$. Skeletal muscle strength was significantly reduced in PAH patients compared with controls, but no significant difference could be detected between patients with WHO FCs II and III, indicating that reduction in peripheral muscle strength was independent of PAH severity.

The physical activity level was lower in PAH patients than in healthy controls. Moreover, frequency of sedentary lifestyle, determined by sitting time per day, was higher among PAH patients. According to categorical classification, physical activity decreased with WHO FC progression. Two other studies also showed decline in physical activity and increase in sedentary time in PAH patients according to NYHA FC ${ }^{23,24)}$. Physical activity measurement is an important outcome in patients with chronic obstructive pulmonary disease $^{25)}$. Like the 6MWT and FC, physical activity also should be routinely assessed and used as an endpoint when evaluating pulmonary rehabilitation programs, especially for patients with a sedentary lifestyle.

This study has some limitations. The sample size was relatively small due to the low incidence of PAH, and the sample of PAH patients was heterogeneous. Future studies are needed to compare functional capacity, physical activity, and respiratory and peripheral muscle strength in the other FCs (I and IV) in various forms of PAH.

In conclusion, the major finding of our study is that as PAH progresses, inspiratory muscle strength, functional exercise capacity, and physical activity decline. The 6MWT, MIP, and IPAQ categorical classification can detect clinically significant changes when comparing patients with WHO FC II and III PAH. Functional capacity, physical activity, and peripheral and respiratory muscle strength are significantly reduced in PAH patients compared with healthy controls. FC and disease severity should be taken into consideration when planning rehabilitation programs for patients with $\mathrm{PAH}$.

\section{REFERENCES}

1) Galiè N, Hoeper MM, Humbert M, et al. ESC Committee for Practice Guidelines (CPG): Guidelines for the diagnosis and treatment of pulmonary hypertension: the Task Force for the Diagnosis and Treatment of Pulmonary Hypertension of the European Society of Cardiology (ESC) and the European Respiratory Society (ERS), endorsed by the Internationa Society of Heart and Lung Transplantation (ISHLT). Eur Heart J, 2009, 30: 2493-2537. [Medline] [CrossRef]

2) Badesch DB, Champion HC, Sanchez MA, et al.: Diagnosis and assessment of pulmonary arterial hypertension. J Am Coll Cardiol, 2009, 54: S55-S66. [Medline] [CrossRef]
3) Looper KJ, Pierre A, Dunkley DM, et al.: Depressive symptoms in relation to physical functioning in pulmonary hypertension. J Psychosom Res, 2009, 66: 221-225. [Medline] [CrossRef]

4) Halank M, Einsle F, Lehman S, et al.: Exercise capacity affects quality of life in patients with pulmonary hypertension. Lung, 2013, 191: 337-343. [Medline] [CrossRef]

5) Fowler RM, Gain KR, Gabbay E: Exercise intolerance in pulmonary arterial hypertension. Pulm Med, 2012,2012:359204.

6) Sato S, Arakawa N, Kamata J, et al.: Relationship between exercise tolerance and respiratory pattern and muscular strength of legs in patients with chronic heart failure. J Phys Ther Sci, 2002, 14: 47-50. [CrossRef]

7) Galiè N, Hoeper MM, Humbert M, et al. Task Force for Diagnosis and Treatment of Pulmonary Hypertension of European Society of Cardiology (ESC) European Respiratory Society (ERS) International Society of Heart and Lung Transplantation (ISHLT): Guidelines for the diagnosis and treatment of pulmonary hypertension. Eur Respir J, 2009, 34: 1219-1263. [Medline] [CrossRef]

8) Miyamoto S, Nagaya $\mathrm{N}$, Satoh $\mathrm{T}$, et al.: Clinical correlates and prognostic significance of six-minute walk test in patients with primary pulmonary hypertension. Comparison with cardiopulmonary exercise testing. Am J Respir Crit Care Med, 2000, 161: 487-492. [Medline] [CrossRef]

9) Flox-Camacho A, Escribano-Subías P, Jiménez-López Guarch C, et al.: Factors affecting the response to exercise in patients with severe pulmonary arterial hypertension. Arch Bronconeumol, 2011, 47: 10-16. [Medline] [CrossRef]

10) Peacock A, Keogh A, Humbert M: Endpoints in pulmonary arterial hypertension: the role of clinical worsening. Curr Opin Pulm Med, 2010, 16: S1-S9. [Medline] [CrossRef]

11) ATS Committee on Proficiency Standards for Clinical Pulmonary Function Laboratories: ATS statement: guidelines for the six-minute walk test. Am J Respir Crit Care Med, 2002, 166: 111-117. [Medline] [CrossRef]

12) Degano B, Sitbon O, Savale L, et al.: Characterization of pulmonary arterial hypertension patients walking more than $450 \mathrm{~m}$ in $6 \mathrm{~min}$ at diagnosis. Chest, 2010, 137: 1297-1303. [Medline] [CrossRef]

13) Saglam M, Arikan H, Savci S, et al.: International physical activity questionnaire: reliability and validity of the Turkish version. Percept Mot Skills, 2010, 111: 278-284. [Medline] [CrossRef]

14) Craig CL, Marshall AL, Sjöström M, et al.: International physical activity questionnaire: 12-country reliability and validity. Med Sci Sports Exerc, 2003, 35: 1381-1395. [Medline] [CrossRef]

15) American Thoracic Society/European Respiratory Society: ATS/ERS Statement on respiratory muscle testing. Am J Respir Crit Care Med, 2002, 166: 518-624. [Medline] [CrossRef]

16) Sugiura H, Ohta $K$, Minatani $S$, et al.: Relationship between respiratory strength and exercise tolerance. J Phys Ther Sci, 2009, 21: 393-397. [CrossRef]

17) Enright PL, Kronmal RA, Manolio TA, et al. Cardiovascular Health Study Research Group: Respiratory muscle strength in the elderly. Correlates and reference values. Am J Respir Crit Care Med, 1994, 149: 430-438. [Medline] [CrossRef]

18) Bohannon RW: Reference values for extremity muscle strength obtained by hand-held dynamometry from adults aged 20 to 79 years. Arch Phys Med Rehabil, 1997, 78: 26-32. [Medline] [CrossRef]

19) Meyer FJ, Lossnitzer D, Kristen AV, et al.: Respiratory muscle dysfunction in idiopathic pulmonary arterial hypertension. Eur Respir J, 2005, 25: 125-130. [Medline] [CrossRef]

20) Kabitz HJ, Schwoerer A, Bremer HC, et al.: Impairment of respiratory muscle function in pulmonary hypertension. Clin Sci (Lond), 2008, 114: 165-171. [Medline] [CrossRef]

21) Bauer R, Dehnert C, Schoene P, et al.: Skeletal muscle dysfunction in patients with idiopathic pulmonary arterial hypertension. Respir Med, 2007, 101: 2366-2369. [Medline] [CrossRef]

22) Mainguy V, Maltais F, Saey D, et al.: Peripheral muscle dysfunction in idiopathic pulmonary arterial hypertension. Thorax, 2010, 65: 113-117. [Medline] [CrossRef]

23) Mainguy V, Provencher S, Maltais F, et al.: Assessment of daily life physical activities in pulmonary arterial hypertension. PLoS ONE, 2011, 6: e27993. [Medline] [CrossRef]

24) Pugh ME, Buchowski MS, Robbins IM, et al.: Physical activity limitation as measured by accelerometry in pulmonary arterial hypertension. Chest, 2012, 142: 1391-1398. [Medline] [CrossRef]

25) Troosters $T$, van der Molen $T$, Polkey M, et al.: Improving physical activity in COPD: towards a new paradigm. Respir Res, 2013, 14: 115. [Medline] [CrossRef] 